ENCYCLOPEEDIE Encyclopédie berbère

BERBERE

$22 \mid 2000$

22 | Hadrumetum - Hidjaba

\title{
Hammam ez Zouakra
}

G. Camps

\section{OpenEdition}

Journals

Édition électronique

URL : http://journals.openedition.org/encyclopedieberbere/1651

DOI : 10.4000/encyclopedieberbere.1651

ISSN : 2262-7197

\section{Éditeur}

Peeters Publishers

\section{Édition imprimée}

Date de publication : 1 janvier 2000

Pagination : 3354-3355

ISBN : 2-7449-0127-X

ISSN : 1015-7344

\section{Référence électronique}

G. Camps, "Hammam ez Zouakra », Encyclopédie berbère [En ligne], 22 | 2000, document H21, mis en ligne le 01 juin 2011, consulté le 25 septembre 2020. URL : http://journals.openedition.org/ encyclopedieberbere/1651; DOI : https://doi.org/10.4000/encyclopedieberbere.1651

Ce document a été généré automatiquement le 25 septembre 2020

(c) Tous droits réservés 


\section{Hammam ez Zouakra}

\section{G. Camps}

1 L'antique Thigibba, station thermale de la région d'Ellès, à l'ouest de Mactar (Tunisie centrale) offre de nombreux exemples de dolmens dont la structure est profondément modifiée. Ces monuments appartiennent à la catégorie des dolmens à portique. Ici le portique est accolé à un ensemble mégalithique complexe de plan rectangulaire. Les monuments occupent les deux versants de la vallée et sont de construction similaire. De plan rectangulaire la sépulture est construite solidement, suivant une technique très répandue chez les Berbères qui consiste à entasser de la pierrailles entre deux murs en pierres équarries. Tandis que le parement extérieur s'élève verticalement, à l'intérieur les assises sont disposées en encorbellement de façon à réduire la surface à couvrir par la dalle supérieure. La chambre carrée est précédée d'un très court vestibule qui servit, peut-être de logement à une herse. A l'extérieur, l'entrée est encadrée par deux piliers sur lesquels repose une dalle qui déborde à l'extérieur ; c'est un procédé habituel dans la construction des dolmens à portique. Il se retrouve dans toute la région de Mactar (Hammam ez-Zouakra, Elles, Maghraoua, Kbour el Ghoul...) 
Dolmen à portique, de plan rectangulaire (d'après L. Frobenius).
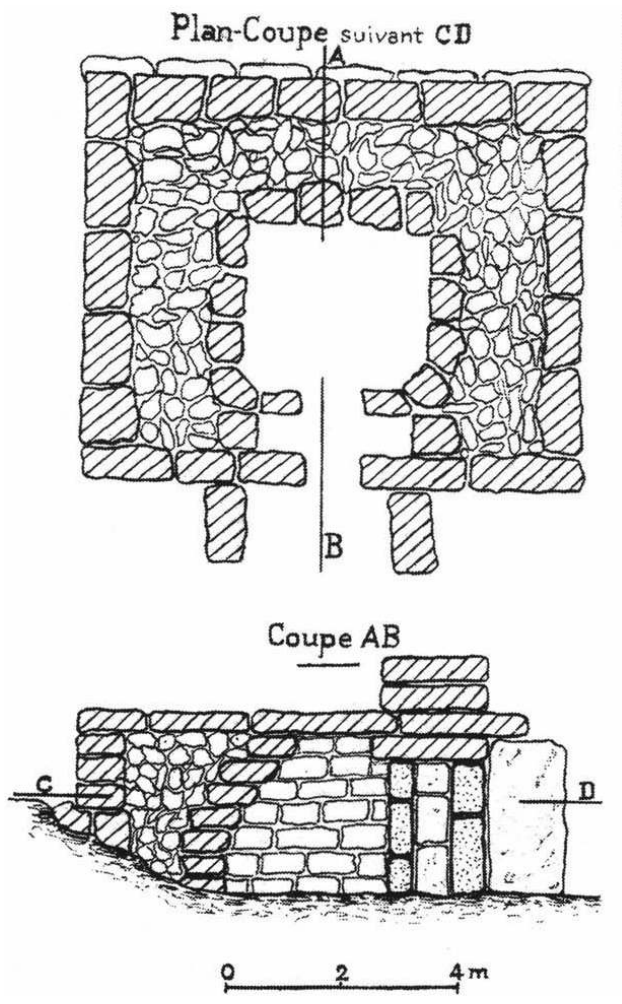

2 Une autre caractéristique des dolmens d'Hammam ez-Zouakra est le décor que certains portent sur la dalle de couverture ou sur les parois; ce sont soit des disques en relief, soit des rosaces, symboles astraux qui se retrouvent dans certains haouanet.

3 Le caractère principal des dolmens de Hammam ez-Zouakra et de la Tunisie centrale reste le portique qui est issu de l'évolution du système de couverture des chambres mégalitiques. Rien ne permet de supposer que cette transformation est due à quelque influence étrangère. Le dolmen à portique de Hammam ez-Zouakra et des autres nécropoles de Tunisie centrale est né sur place ; adoptant "l'appareil berbère" pour ses murs, transformant le couloir en vestibule, choisissant une dalle de couverture plus étendue que ne l'exigeait la protection de la chambre funéraire, il ne garde du schéma dolménique que cette couverture débordante.

\section{BIBLIOGRAPHIE}

DE RIALlE G., “Monuments mégalithiques de Tunisie”, Bull des Antiq. afric, H, p. 260-268.

TISsот Ch., Géographie comparée de la province romaine d'Afrique, t. II, 1888, p. 626-628.

DENIS Ch., "Les dolmens de la Tunisie centrale", Bull. de la Soc. de Géogr. et d'Archéo. d'Oran, t. XV, 1895 , p. 273-280.

Cdt ToussAinT, “Rapport archéologique sur la région de Macta”, BCTHS, 1899, p. 131. 
FROBENIUS L., 'Der Klein Afrikanische grabbau”, Pracestorische Zeitschrifte, 1916, p. 53.

Cne FOUSSARD, "Exploration archéologique du terrain compris sur la carte de Mactar au 1/50000", BCTHS, 1923, p. 51-56.

GSELL S., Histoire ancienne de l'Afrique du Nord, t. VI, 1929, p. 204-205.

TOUTAIN J., "Compte-rendu du rapport du Colonel Reyniers sur les fouilles exécutées à Hammam Zouakra", BCTHS, 1948, p. 46-47.

PAUPHILET D., “Monument mégalithique à Mactar", Karthago, t. IV, 1953, p. 49-83.

CAMPS G., Aux origines de la Berbérie. Monuments et rites funéraires protohistoriques, 1961, p. 188-190.

Atlas préhistorique de la Tunisie, feuille 8, Maktar, p. 30-31.

INDEX

Mots-clés : Archéologie, Tunisie, Préhistoire 